\title{
School Readiness from Kindergarten to Primary School
}

\author{
https://doi.org/10.3991/ijet.v14i11.10090 \\ Georgia Kokkalia $^{\left({ }^{\infty}\right)}$, Athanasios Drigas \\ NCSR Demokritos, Athens, Greece \\ gioulina@hotmail.com \\ Alexandra Economou, Petros Roussos \\ University of Athens, Athens, Greece
}

\begin{abstract}
The current paper review gives a brief and representative description of the role that school readiness from kindergarten education to primary education plays in every child's academic life. Therefore many researchers note that school readiness tools play a notable role for the kindergarten teachers, the family and of course for the child in order to achieve a successful school life. Thus, the research team of this paper gives the presentation of some school readiness tools that are used by kindergarten teachers and specialist's worldwide scoping to underlie strengths and weaknesses of preschoolers. Additionally, it is thought worthwhile to say that the readiness tools that are presented are used with the traditional way while some of them with the support of new technology. Lastly, the theoretical base of the significant role that school readiness plays from kindergarten to first grade and its crucial role for the child's academic development is discussed shortly.
\end{abstract}

Keywords—Kindergarten education, primary education, school.

\section{$1 \quad$ Introduction}

According to many studies school readiness seems to be a very crucial issue for a child' s academic development and researchers view school readiness as children possessing the skills, knowledge, and attitudes necessary for success in school and for later learning and life. Furthermore, latest studies believe that school programs with the support of the governments must establish school readiness goals that are appropriate for the ages and development of enrolled children in domains that are essential for it [1].

Modern definitions of school readiness divide the construct into three interrelated but conceptually distinct aspects. Child school readiness is the child's level of development across multiple domains needed for optimal performance in school. This incorporates physical well- being, motor development, social and emotional development, language and speech development, general knowledge and cognition, and other related subdomains. A second aspect, the school's institutional readiness refers to school policies and practices to welcome and educate children at various stages of development in multiple domains. Finally, familial and community school readiness 
refers to the ability of the family and community to support optimal early child development starting prenatally until the child enters kindergarten [2].

The transition between educational grades is a critical period for children, parents, teachers and schools [3]. Today, nearly all children attend a public or private kindergarten before first grade and as kindergarten enrollments have grown, the range of kindergarten programs stress academic skills that were previously reserved for older children [4]. This transition from kindergarten to primary school constitutes a significant point in children's development, entailing definitive effects on their personality and the formation of their behavior, but also on their school performance. Innovative educational programs, tools and studies constitute a nodal point for the development of cooperation among the educational institutions, aiming to facilitate the transition procedure. In particular, the parents and teachers are concerned about the transition to first grade in which young children will be engaged in more academic activities, which requires the child to be well prepared [5].Taking the above into account, Zuckerman\& Halfon [6] state that kindergarten readiness is a child's ability to demonstrate the foundational knowledge, skills, and behaviors in key areas and domains of learning that prepare him/her for curriculum based on the kindergarten standards.

Consequently, understanding how young children are best prepared to enter and succeed in grade school has become a priority among parents, educators, legislators and researchers. To a large extent, contemporary efforts to address this agenda have been guided by this concept of school readiness. As many researchers, practitioners, and policy-makers have defined it, school readiness implies that by the time children enter Kindergarten they have achieved a level of development that makes it likely that they will successfully adapt to the challenges of formal schooling. Whether intended or not, this concept implies that an important objective for the early childhood years is to ensure that young children achieve a state of readiness before they enter grade school. In practice, however, this objective has proven difficult to achieve. Every year, large numbers of children have difficulty adapting to grade school, and these data make it clear that there is considerable variation in the extent to which young children are prepared for formal schooling. Most often, deviations from this implied norm are attributed to differences in children's rearing conditions (e.g. poverty, violence in the community or home, inadequate or dysfunctional socialization), health (developmental delays, disabilities, injuries, chronic illness), inherited characteristics (e.g. ability, temperament, personality), and various combinations of these factors. So it is obvious that school readiness not only consists of the development of cognitive and literacy skills [3] but covers all developmental domains of children such as physi$\mathrm{cal}$, social, emotional and language. The main aim of the readiness process is to provide children with a smooth transition to first grade and thus preschool education is thought to be important for the smooth transition to it [4].

In the light of the above statements, in this project we will try to present a short introduction about the role of school readiness from kindergarten to primary school and a brief list of some of the most well known traditional and information communication tools that are used for the detection of the school readiness of kindergarten students in order to have a successful transition to the next grade. 


\section{The Ambiguous Concept of School Readiness}

The concept of "school readiness" has a number of different understandings and interpretations in the context of early childhood education practice. One common nativist view of readiness supports the view that children are ready to start school when they reach a level of maturity in order to sit quietly, focus on work, engage with their peers in socially acceptable ways, and accept directions and rules from teachers and other important for them adults [7]. On the other hand, an empiricist conception of readiness sees readiness entirely in terms of the practical characteristics of the child's behaviors and focuses on the external evidence of learning. A different approach emerges from the perspective that takes seriously the basic relativity that characterizes readiness among young children and sees readiness in social and cultural terms. A researcher supported the idea that readiness is "a set of ideas or meanings constructed by people in communities, families, and schools as they participate in the kindergarten experience. These ideas come out of community values and expectations and are related to individual children in terms of attributes like their age, sex, and preschool experience. This view shifts the focus of assessment away from the child to the community in which the child is living. Specifically, perceptions of teachers, parents, and others regarding a child's readiness become the foreground for this discussion [8].

Additionally, researchers [9] note that developmental status does not determine readiness because the skills and abilities necessary for school success may vary substantially from one school to another, or even more from one classroom to another within a school. For a given set of school expectations, there can even be considerable variation in the specific skills and abilities that lead to successful school performance [9]. Because of these factors, the typical readiness definition provides little or no guidance about how to resolve differences that are found among communities, schools, or even classrooms. So, the final perspective on school readiness focuses on children's learning and on schools' capacities to meet the individual needs of their students. Rather, it is the product of a set of educational decisions that are differentially shaped by the skills, experiences, and learning opportunities the child has had and the perspectives and goals of the community, classroom, and teacher. In other words, readiness is no longer mainly seen as a condition of the child. It is also being seen as a condition of families, of schools, and of communities [10].

However, many researchers [11] have focused largely on the importance of cognitive skills and emergent literacy for later academic achievement despite the fact that children's school readiness is viewed as multidimensional, encompassing also socialemotional development and health. The National Education Goals Panel identified some crucial developmental domains associated with early development and learning such as physical well- being and motor development, socio-emotional development, approaches to learning, language development, and cognitive and general knowledge [12].

More specifically, physical well- being and motor development encompass those characteristics as rate of growth, physical fitness, chronic conditions, fine and gross motor skills, and self-care abilities. Despite the importance of physical well being for children's ability to perform well in school, studies of school success often neglect to 
examine the influence of health, disabilities, and health care on achievement [13]. Moreover, social-emotional competency is also important for success in classroom settings and mainly the ability to regulate one's emotions and behavior supports a child's ability to pay attention, follow directions, and cooperate and collaborate with peers and teachers on joint activities[14] ). In fact, parents and teachers often agree that the most important school readiness skills children can have as they enter kindergarten are social interaction skills such as listening, following directions, communicating verbally about needs/thoughts, taking turns and sharing, complying with teacher authority, not being disruptive, and being sensitive to others [15]. Additionally, language development that includes understanding spoken language, using spoken language to accomplish tasks, developing a broad vocabulary, developing an interest in books and stories, understanding the purpose of print, understanding that stories follow a standard sequence, recognizing the letters and sounds of a language, beginning writing skills and early literacy skills are understood to be foundational to children's academic success. Lastly, cognition and general knowledge encompasses knowledge of the properties of objects (such as color and weight) an understanding of the relationships between objects, events, and the acquisition of the conventions of society or school-learned knowledge [16].

In the light of the above, a study by Hair et al. [17] showed that learning profiles differentially predicted academic and social adjustment in early elementary school, even after controlling for demographic background characteristics. These results suggest that school readiness skills do cluster within individuals in distinct patterns and that they differentially predict outcomes in later schooling. This study also suggests that health and social-emotional wellbeing are important aspects of school readiness to consider along with language and literacy skills.

However, children often demonstrate different readiness particularly in the cognitive and socio emotional skills [18] and smooth transition to school is thought important because the child's readiness can predict their performance in the near future. Children who are less ready are likely to succeed academically and less likely to experience behavioral and emotional problems while they are less likely to be school dropouts [16]. In addition, children who are less prepared for school are more likely to become teen parents, engage in criminal activity, and have a job that did not survive [19]. Therefore, school readiness of children can enhance academic achievement and the development of children's. Their readiness varies according to the current experience in pre-school, pre-school locations, and educational background and economic status of parents while such variation affects human capital development as academic achievement and future career success can be predicted based on their readiness to school [20].

\section{The Role of School Readiness from Kindergarten to Primary School}

If you are using Word, use either the Microsoft Equation Editor or the MathType add-on (http://www.mathtype.com) for equations in your paper (Insert | Object | Cre- 
ate New | Microsoft Equation or MathType Equation). "Float over text" should not be selected.

In recent years, many debates have taken place about how best to promote young children's school readiness [21] Many of the most respected early childhood interventions depend on child-centered programs, with teachers and other service providers working directly with children [22]. Thus, the emergence of universal kindergarten programming intend to promote specific language, literacy, socio emotional, and mathematical skills in preschool children through intensive, child-centered instructional experiences delivered in school based instructional settings [23] As such, early childhood educators provide enriched educational experiences for children who are expected to acquire and develop necessary skills for school success. A broader perspective on school readiness argues the necessity of considering the surrounding contexts, roles, and relationships that collectively interact to influence child and family development such as the articulation of specific responsibilities shared among professionals, home visitors, teachers, parents, and extended family members [24]

Young children who enter kindergarten behind their peers in academic and socialemotional school readiness skills are at risk for long-term negative school outcomes [25] Because the majority of children spend substantial time in pre- school prior to kindergarten entry [26] the preschool classroom is an important context in which to provide learning experiences that foster school readiness. Two aspects of the quality of children's preschool classroom experience (an individual child's engagement and interaction with the environment provided and the teacher's capacity to provide a stimulating environment) are critical because they represent the proximal mechanisms by which children learn new academic and social-emotional skills. How an individual child engages with teachers, peers, and learning activities in the classroom relates to school achievement and adjustment [27] However, most of the research examining the impacts of early education and childcare experiences on young children's outcomes has been conducted at the classroom level [28], demonstrating that a teacher's capacity to provide a supportive and stimulating early childhood education experience through her interactions with children is positively associated with gains in school readiness skills. To date, however, few studies have examined children's preschool experience from both the perspective of how the individual child engages and the perspective of what the teacher provides [28].

This opinion is supported by Erkan and Kurca [29] who searched the effect of preschool education on young children's school readiness and found that children who had preschool experience were more ready than other peers. Also, Aboud and Hossain [30] emphasized that preschool education increased children's academic success in further education. Furthermore, in the available research, certain important points were made concerning children's readiness for first grade and facilitating the transition between grades resulting that consistency and persistence between programs of two grades makes the readiness process more meaningful and supports easy transition. The literature review showed also that the teacher is a key factor for the smooth and happy transition of children to the next grade [31] 
Nevertheless, physical, motor, language, literacy, math, fine arts, cognitive, social, and emotional development seem to be essential ingredients for children's enrollment in primary school.

Kindergarten programs assume, that each student must follow simple directions, has a basic understanding of feelings and reasonable ability to cooperate during classroom activities, communicates needs, hop, skip, use pencil and scissors, recognizes shapes, colors, numbers 1-10, letters and can distinguish sounds. Also, approaches to learning from children have been found to support important domains of learning, particularly academic skills such as reading and math achievement. As a result kindergarten children should use such approaches to learning) including intrinsic motivation to learn, interest and joy in learning, engagement, persistence, task orientation, planning, ability to focus and control attention, flexible problem solving, inventiveness, and tolerance for frustration [32].

\section{Traditional Tools for School Readiness from Kindergarten to Primary School}

Taking into consideration the available tools that are used in the Greek educational system and worldwide we will try to present some traditional tools that examine the school readiness from kindergarten to primary education. In addition, the domains that were mentioned above and are essential for a smooth and easy transition for preschoolers to the first grade will be explored in order to have trustworthy and valid results through these tools for school readiness.

The Boehm Test of Basic Concepts-3 (Boehm-3) and Boehm Test of Basic Concepts-3 Preschool (Boehm-3 Preschool) were designed to assess young children's understanding of basic relational concepts important for language and cognitive development, as well as success in school across all learning areas [33]. The major purpose of each level of the test is to identify gaps in learning to guide instruction and intervention during a child's schooling toward success. Classroom teachers, speechlanguage pathologists, school psychologists, and other special education professionals can all use and benefit from this knowledge about the students they teach. The Boehm-3 covers 50 concepts that appear in print materials, reading and mathematics curricula, and professionals' verbal instructions for kindergarten through secondgrade students. The test is group administered but can be individually administered as a criterion referenced measure to older children who have special needs. Two parallel forms of the test include English and Spanish norms for fall and spring. Assessing the whole class early in the fall offers professionals a quick picture of the students' proficiency in concept understanding for instructional planning. In the spring, use of the alternate form of the test makes assessment of progress easy and accurate. Validity was established by review of mathematics and reading curricula and concepts used by teachers when giving instructions. The Boehm-3 Preschool is an individually administered test that covers 26 concepts at each of two age levels ( 3 years 0 months to 3 years 11 months; 4 years 0 months to 5 years 11 months) and is also appropriate, as a criterion-referenced measure for older children who have special needs. Each concept 
is assessed twice to identify concepts that are emerging, concepts that the child knows, or concepts that need development. English and Spanish norms are presented at 6-month age bands. The child responds to verbal instructions by pointing to one of four options on a picture [34]. Finally, the Boehm-3 can be used to identify students who may be at risk for a learning difficulty and may need referral for additional testing, to identify students in the classroom who know most concepts, but are having difficulty understanding a few key concepts that are embedded in instruction, for preand post-testing to determine progress as a result of instruction or intervention and finally as part of a battery of tests to assess students' language comprehension skills [35].

Alpha test-Screening test for school readiness [36] is a very short screening test for children 5-6 years that examines the learning and emotional readiness of a child for elementary school, so as to prevent school failure and serious social and mental disturbances. It is not an intelligence test and its evaluation is computer-based. The Alpha Test checks school readiness, hyperactivity / distraction and test behavior as a standard multi-subject test that evaluates the child's learning ability through two communication paths: Acoustics / Linguistics and Optical-perceptual. The first evaluates, the Verbal Skill, (e.g. the child's ability to handle speech and words) while the latter assesses the Practical Skill, (e.g. what the child can do with his / her hands). As it is well known that learning ability is a complex function involving many individual competencies the test should include individual scales that will assess these many different abilities. All together determine the child's ability to join the school program successfully. A 'TEST comprises 7 individual scales, which Evaluate different learning and cognitive functions, namely: Critical ability, Linguistic analogies, Early Abstract Thinking, Visual-Kinetic Co-ordination, Optical Concept, Broad Mobility and Sequences. Each of the individual scales of school readiness is graded with a specific numeric index. From the statistical and cumulative processing of the individual specific numerical indices, a numerical set of units is expressed, which expresses the school's overall readiness for the child as a whole. All units correspond to a specific developmental cognitive age. The ability to evaluate the test on a scale but at the same time as a whole is important because it allows to identify areas of child development that require particular attention. Moreover, the ability to evaluate the test on a scale but at the same time as a whole is important because it allows to identify areas of child development that require particular attention. A 'TEST is a screening test that provides high level information with significant predictive validity in terms of the child's future learning ability. Its biggest advantage is that it can be applied as a preventative - detection tool, easily, quickly, reliably in large child populations. The structure of the test offers the examiner the ability to evaluate the findings both overall and individually, on a scale, as depicted in the child's internal diagram. By granting TEST, the examiner can, within a short period of time, "detect" objective information about the child's developmental abilities and attempt a proposal for full developmental control where it is deemed necessary. Finally, A 'TEST can also help educators to properly inform and advise parents to deal with difficulties with special and /or special treatment programs (speech therapy, occupational therapy, special treatment. 
The Early Childhood Skills Assessment Scale is a weighted screening process that can be used to identify children in high-risk groups for special educational needs, and assess their learning outcomes [37] It is also a useful guide to grouping children, based on their learning potential, if deemed necessary by the preschool teacher. The Scale provides a focused basis for assessing the linguistic, mathematical, social, motor skills of children as well as their learning autonomy skills. The individual profile that results from the assessment describes the potential and the difficulties of each child in the above development areas, which can be correlated with his performance in the classroom. In this way, it is possible to locate the cognitive areas in which each child presents difficulties or deficits and facilitates the individualized or group intervention for the benefit of the children and the learning process at this school level. Finally, educators with the traditional way can use the scale for kindergarten children [38].

The Work Sampling System is an instructional assessment that is used in preschool through third grade and is a criterion-referenced observational assessment with extensive research supporting reliability and validity. Its purpose is to document and assess children's skills, knowledge, behavior, and accomplishments across a wide variety of curriculum areas on multiple occasions in order to enhance teaching and learning [39]. The Work Sampling System consists of three complementary elements: 1) Developmental Guidelines that cover seven major curriculum areas: personal and social development; language and literacy; mathematical thinking; scientific thinking; social studies; the arts; and physical development, health and safety. 2) Developmental Checklists that are customized for each grade level and 3) Summary Reports which replace conventional report cards as a way of recording progress, communicating with parents, and meeting reporting requirements. Using information from the Developmental Checklists, you can complete a Summary Report three times a year. The Work Sampling System calls for ongoing assessment that is summarized three times per year. By reflecting classroom goals and objectives, it helps teachers monitor children's continuous progress and places children's work within a broad developmental perspective. Through documenting and evaluating individual performance of classroom-based tasks, Work Sampling strengthens student motivation, assists teachers in instructional decision making, and serves as an effective means for reporting children's progress to families, educators, and community. More specifically, this tool collects information on the child's work and compares it to grade-specific guidelines, identify what children are learning, what they are beginning to master, and what they still need to work on offering the teacher a useful instruction planning. [40]

Lastly, the Early Screening Inventory-Revised (ESI-RTM) 2008 Edition provides a brief developmental screening instrument designed to be individually administered to children from 3.0 to 5.11 years of age. It identifies children who may need special education services in order to perform successfully in school. The instrument addresses developmental, sensory, and behavioral concerns in the following areas: visual motor skills, language and cognition and gross motor skills [41]. 


\section{ICT Tools for School Readiness from Kindergarten to Primary School}

The adoption of information and communication technology (ICT) in early childhood educational settings is of international interest. ICT in education is promoted by the United Nations Educational Scientific and Cultural Organisation as a way ofaccess, inclusion and quality [42]. This is being attended to by many countries as they move to integrate ICT-specific guidelines in the various national education frameworks which influence early childhood educational institutions. A large number of studies have highlighted the importance of smooth preschool-to-school transition and the successful first years of schooling from different perspectives. Research has paid increasing attention to identifying the conditions of a successful start in schooling. Among these efforts, creating instruments for assessing school readiness and monitoring development at the beginning of schooling play an important role. A broad range of instruments, including observation protocols, tests, and test batteries, are available, which can be used to assess different aspects of general cognitive development as well as specific precursors of skills learners are expected to master at school. However, many instruments that have been proven valid and reliable under research or pilot conditions turn out to be too complicated to use regularly in schools. Some- times they are not sufficiently precise if not used under standardized conditions or if not administered by specially trained teachers. In many cases, technology-based assessment may solve these problems [42].

Although the majority of studies on school readiness assessment have focused on the cognitive domain, recent research identified several further factors, which play a crucial role in kindergarten- school transition and later development, such as selfconcept, peer status, classroom contexts, and parenting [43]. Although there are still a number of open questions related to certain details of the content of school readiness assessment and the ways their data may be used there is a consensus that the availability of appropriate and easy-to-use measurement instruments is crucial to helping children to begin school successfully and to identify those who are in need of additional support [44].

Despite these constraints, a number of school readiness assessments are based on the direct observation of children [45]. The Performance Indicators in Primary Schools (PIPS) tests are used to monitor children's development in the early years of primary school. Its Baseline Assessment (PIPS BLA) measures early reading, mathematics, phonological awareness and personal, social, and emotional development. This instrument was used in a large-scale international study (iPIPS) to compare children's early development in English-speaking countries [46].

Moreover, in educational practice, the DIFER is a tool that can be used as a diagnostic instrument for school readiness. Children are assessed regularly over time, and a record of their development is kept in a booklet. The development of those who lag behind may be stimulated by special purpose exercises. The DIFER is designed so that its administration does not require specific expertise as kindergarten and primary school teachers can administer it. A major drawback of the test battery is that it must be administered face to face and individually. An online delivery of prerecorded voice 
instructions (with texts read by trained speakers) and automated scoring may solve these problems. As two out of the seven DIFER tests (social skills and writing) cannot be immediately digitized, the remaining five (speech sound discrimination, relational reasoning, deductive reasoning, inferential reasoning, and counting skills) were transferred to an online platform [47].

The Early Development Instrument (EDI) measures children's school readiness prior to Grade 1 entry in five areas of development: physical, social, emotional, language and cognitive, as well as communication. EDI data in kindergarten were linked to Grade 3 reading, writing and math standardized achievement scores for 45,000 kindergarten students in Ontario, Canada to investigate the impact of kindergarten abilities on later academic achievement. Multi-level regression models showed that the cognitive domains had the strongest correlations with reading, writing, and math with the largest coefficients, controlling for individual and school-level demographic factors, but the physical, social, and emotional domains also were significantly associated with achievement scores, independent of cognitive readiness. The effect sizes of the non-cognitive domains' impact were comparable to or larger than variables such as gender or first language. These findings demonstrate the importance of holistic measures of school readiness, encompassing cognitive and non-cognitive areas, for understanding early achievement and potential prevention of continuing underachievement [48].

Lastly, an interesting and important tools is The Getting Ready intervention, an integrated, multi-systemic, ecologically based intervention that promotes school readiness through enhancing parent engagement for children from birth to age five [49]. As a model of practice, Getting Ready promotes professional behavior that supports parents' competence and confidence in their interactions with their children within the context of cultural and family practices and values. The model is focused on supporting the dyadic parent-child relationship, and an exchange of ideas and developmentally appropriate expectations for children between parents and early childhood professionals (ECPs). Triadic and collaborative [50] strategies are used by professionals which involve establishing relationships, maintaining positive communication, asking for and building on parental observations of child development, recognizing parental strengths and offering affirmations, supporting parents via the provision of developmental information, and encouraging them to discuss and prioritize concerns and needs for their child while at the same time focusing on child strengths. Specifically, ECPs observe parent-child interactions frequently, often in home settings, in an effort to sup- port parental practices and interactions with their children. Additionally, ECPs brainstorm effective approaches to support children's development, model strategies that have been shown to advance children's attention, motivation, and understanding of new concepts and skills, and provide feedback (affirmations, suggestions, and demonstrations) on parental efforts to engage children in natural and structured learning opportunities. Children's responses are noted, and the need for adjusting intervention components is discussed based on these shared observational data, and plans for future directions are developed [50]. 


\section{Conclusion}

A number of bibliographic and research findings in the field of education and developmental psychology underline the substantial effect that a variety of factors exert on the smooth transition of children from kindergarten to elementary school, such as the individual characteristics of the child, the characteristics of the school and the class which welcomes the child, the family and social environment of the child. School readiness is increasingly being studied in relation to the characteristics of the child itself that affect his / her school functionality. These factors such as intelligence and learning abilities, difficulties, age, motivation, personality, child mental health, the behavior of the teacher to that and the characteristics of the family context in which he develops have become a subject of particular research interest that investigates the role of school readiness to the level of school or learning progress of a child [51].

Although each child is unique and develops at his or her own pace, most educators and developmental experts agree upon a certain set of skills as essential tools for further development and achievement in school. School readiness is among the nation's top priorities, and parents, educators, practitioners and policymakers are all stakeholders in research on the early precursors to children's academic success. School readiness is a multidimensional construct that was defined in the National Education Goals Panel report as consisting of specific major components such as language use, cognition and general knowledge, physical health and well-being, social and emotional development, and approaches to learning. These components are usually thought as the key to children's successful transition from kindergarten to the primary school years [52].

This research theme has emerged from the review of Greek and foreign literature on the smooth or non-transition of a child from kindergarten to elementary school and the factors contributing either positively or negatively to it. References to the international bibliography on the transition period vary. Some writers face it as a necessary challenge for children-students, which will enable them to grow, learn and be more flexible in the future, while others emphasize the existence of continuity in life and their education. However, it is generally accepted that the first learning experiences have a catalytic effect on shaping the deeper characteristics of a child's personality but also on his further academic development and on his later physical, mental and emotional development. The experiences acquired by a child in the context of a school reality, which he / she is called to face on a daily basis, influence his or her attitude, his / her attitude towards school and his / her efficiency and the creation and preservation of his or her will for learning [53],[54].

As a result, in this article we tried to present briefly the significant role that school readiness plays from kindergarten to primary education and how this concept may enhance academic and learning development in kindergarten children. Additionally, some important and significant traditional and ict tools were examined in order to see how these tools work and how their results may help teachers, therapists and other experts to promote the right and appropriate guidance to their students. The findings 
of our review noted the role that these tools play for the development of the child and the role of the kindergarten education for the later academic progress of a child.

\section{$7 \quad$ References}

[1] Mills, C. W. (2000). The sociological imagination. Oxford University Press.

[2] Halle, T. G., Hair, E. C., Wandner, L. D., \& Chien, N. C. (2012). Profiles of school readiness among four-year-old Head Start children. Early Childhood Research Quarterly, 27(4), 613-626. https://doi.org/10.1016/j.ecresq.2012.04.001

[3] Winter, S. M., \& Kelley, M. F. (2008). Forty years of school readiness research: What have we learned?. Childhood Education, 84(5), 260-266. https://doi.org/10.1080/00094056.2008.10523022

[4] Wang, J., Elicker, J., McMullen, M., \& Mao, S. (2008). Chinese and American preschool teachers' beliefs about early childhood curriculum. Early Child Development and Care, 178(3), 227-249. https://doi.org/10.1080/03004430600722671

[5] DiBello, L. C., \& Neuharth-Pritchett, S. (2008). Perspectives on school readiness and prekindergarten programs: An introduction. Childhood Education, 84(5), 256-259. https://doi.org/10.1080/00094056.2008.10523021

[6] Zuckerman, B., \& Halfon, N. (2003). School readiness: an idea whose time has arrived. Pediatrics, 111(6), 1433-1436. https://doi.org/10.1542/peds.111.6.1433

[7] Barnett, W. S. (2004, November). Maximizing returns from prekindergarten education. In Federal Reserve Bank of Cleveland research conference: Education and economic development (pp. 5-18).

[8] Dockett, S., \& Perry, B. (2002). Who's ready for what? Young children starting school. Contemporary Issues in Early Childhood, 3(1), 67-89. https://doi.org/10.2304/ciec.2002.3.1.9

[9] Brooks-Gunn, J., \& Markman, L. B. (2005). The contribution of parenting to ethnic and racial gaps in school readiness. The future of children, 139-168. https://doi.org/10.1353/foc.2005.0001

[10] Drigas, A., \& Kokkalia, G. (2014). Icts in kindergarten. International Journal of Emerging Technologies in Learning (iJET), 9(2), 52-58. https://doi.org/10.3991/ijet.v9i2.3278

[11] McMaken, J., Kauerz, K., DeCesare, D., \& Hale, G. (2002). Technology and Early Childhood Professional Development: A Policy Discussion.

[12] Kagan, S. L. (2003). Children's readiness for school: Issues in assessment. International Journal of Early Childhood, 35(1-2), 114.

[13] Ikeshita, H., Yamaguchi, S., Morioka, T., \& Yamazoe, T. (2018). Effects of Highlighting Text on the Reading Ability of Children with Developmental Dyslexia: A Pilot Study. International Journal of Emerging Technologies in Learning (iJET), 13(09), 239-251. https://doi.org/10.3991/ijet.v13i09.8736

[14] Thompson, R. A., \& Lagattuta, K. H. (2006). Feeling and understanding: Early emotional development. Blackwell handbook of early childhood development, 317-337. https://doi.org/10.1002/9780470757703.ch16

[15] Wesley, P. W., \& Buysse, V. (2003). Making meaning of school readiness in schools and communities. Early Childhood Research Quarterly, 18(3), 351-375. https://doi.org/10.1016/s0885-2006(03)00044-9

[16] Duncan, G. J., Dowsett, C. J., Claessens, A., Magnuson, K., Huston, A. C., Klebanov, P., ... \& Sexton, H. (2007). School readiness and later achievement. Developmental psychology, 43(6), 1428. https://doi.org/10.1037/0012-1649.43.6.1428

[17] Hair, N. L., Hanson, J. L., Wolfe, B. L., \& Pollak, S. D. (2015). Association of child poverty, brain development, and academic achievement. JAMA pediatrics, 169(9), 822-829. https://doi.org/10.1001/jamapediatrics.2015.1475

[18] Smart, D., Sanson, A., Baxter, J., Edwards, B., \& Hayes, A. (2008). Home-to-school transitions for financially disadvantaged children. Book Home-To-School Transitions For Financially Disadvantaged Children (Editor ed.^ ${ }^{\wedge}$ ds.). 
[19] Schweinhart, L. J. (2003). Benefits, Costs, and Explanation of the High/Scope Perry Preschool Program.

[20] Kokkalia, G., Drigas, A., \& Economou, A. (2016). The role of games in special preschool education. International Journal of Emerging Technologies in Learning (iJET), 11(12), 3035. https://doi.org/10.3991/ijet.v11i12.5945

[21] Vernon-Feagans, L., \& Blair, C. (2006). Measurement of school readiness. Early Education and Development, 17(1), 1-5. https://doi.org/10.1207/s15566935eed1701 1

[22] Mahoney, G., O'Sullivan, P., \& Dennebaum, J. (1990). Maternal perceptions of early intervention services: A scale for assessing family-focused intervention. Topics in Early Childhood Special Education, 10(1), 1-15. https://doi.org/10.1177/027112149001000102

[23] Emrouznejad, A., Parker, B. R., \& Tavares, G. (2008). Evaluation of research in efficiency and productivity: A survey and analysis of the first 30 years of scholarly literature in DEA. Socio-economic planning sciences, 42(3), 151-157. https://doi.org/10.1016/i.seps.2007.07.002

[24] Mashburn, A. J., \& Pianta, R. C. (2006). Social relationships and school readiness. Early education and development, 17(1), 151-176. https://doi.org/10.1207/s15566935eed1701 7

[25] Magnuson, K. A., Ruhm, C., \& Waldfogel, J. (2007). Does prekindergarten improve school preparation and performance?. Economics of Education review, 26(1), 33-51. https://doi.org/10.1016/i.econedurev.2005.09.008

[26] Adams, G. (2007). Early care and education for children in low-income families: Patterns of use, quality, and potential policy implications. https://doi.org/10.1037/e688192011-001

[27] Fredricks, J. A., Blumenfeld, P. C., \& Paris, A. H. (2004). School engagement: Potential of the concept, state of the evidence. Review of educational research, 74(1), 59-109. https://doi.org/10.3102/00346543074001059

[28] Phillips, D. A., Fox, N. A., \& Gunnar, M. R. (2011). Same place, different experiences: Bringing individual differences to research in child care. Child Development Perspectives, 5(1), 44-49. https://doi.org/10.1111/j.1750-8606.2010.00155.x

[29] Drigas, A., \& Dourou, A. (2013). A Review on ICTs, E-Learning and Artificial Intelligence for Dyslexic's Assistance. International Journal of Emerging Technologies in Learning (iJET), 8(4), 63-67. https://doi.org/10.3991/ijet.v8i4.2980

[30] Aboud, F. E., \& Hossain, K. (2011). The impact of preprimary school on primary school achievement in Bangladesh. Early Childhood Research Quarterly, 26(2), 237-246. https://doi.org/10.1016/i.ecresq.2010.07.001

[31] Morrison, G. R., Ross, S. M., Kalman, H. K., \& Kemp, J. E. (2012). Designing effective instruction. Wiley.

[32] Hyson, M. (2008). Enthusiastic and engaged learners: Approaches to learning in the early childhood classroom. Teachers College Press.

[33] Boehm, A. E. (1971). Boehm test of basic concepts. New York: Psychological Corporation.

[34] Spector, C. C. (1979). The Boehm Test of Basic Concepts: Exploring the test results for cognitive deficits. Journal of Learning Disabilities, 12(8), 564-567. https://doi.org/10.1177/002221947901200813

[35] McDermott, P. A., \& Beitman, B. S. (1984). Standardization of a scale for the study of children's learning styles: Structure, stability, and criterion validity. Psychology in the Schools, 21(1), 5-14. https://doi.org/10.1002/1520-6807(198401)21:1<5::aidpits2310210102>3.0.co;2-

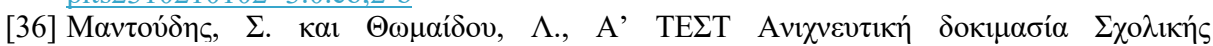

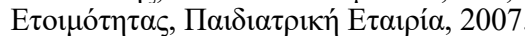

[37] Ralli, A. M. and Maridaki Kassotaki, A., Rating scale for the assesment of preschool children (In Greek), 2011.

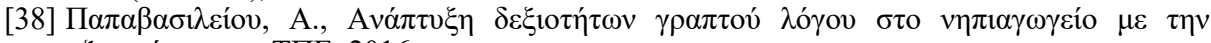

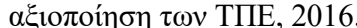

[39] Meisels, S. J., Liaw, F. R., Dorfman, A., \& Nelson, R. F. (1995). The Work Sampling System: Reliability and validity of a performance assessment for young children. Early Childhood Research Quarterly, 10(3), 277-296. https://doi.org/10.1016/0885-2006(95)90008-x

[40] Meisels, S. J. (1995). Performance Assessment in Early Childhood Education: The Work Sampling System. ERIC Digest. 
[41] Ringwalt, S. (2008). Developmental Screening and Assessment Instruments with an Emphasis on Social and Emotional Development for Young Children Ages Birth through Five. National Early Childhood Technical Assistance Center (NECTAC).

[42] Mashburn, A. J., \& Henry, G. T. (2004). Assessing school readiness: Validity and bias in preschool and kindergarten teachers' ratings. Educational Measurement: Issues and Practice, 23(4), 16-30. https://doi.org/10.1111/i.1745-3992.2004.tb00165.x

[43] Divayana, D. G. H., \& Sanjaya, D. B. (2017). mobile phone-based cipp evaluation model in evaluating the use of blended learning at school in Bali. International Journal of Interactive Mobile Technologies (iJIM), 11(4), 149-159.

[44] Snow, K. L. (2006). Measuring school readiness: Conceptual and practical considerations. Early education and development, 17(1), 7-41. https://doi.org/10.1207/s15566935eed1701 2

[45] Guhn, M., Janus, M., \& Hertzman, C. (2007). The Early Development Instrument: Translating school readiness assessment into community actions and policy planning. Early Education and Development, 18(3), 369-374. https://doi.org/10.1080/10409280701610622

[46] Tymms, P., Merrell, C., Hawker, D., \& Nicholson, F. (2014). Performance indicators in primary schools: A comparison of performance on entry to school and the progress made in the first year in England and four other jurisdictions.

[47] Senge, P. M., Cambron-McCabe, N., Lucas, T., Smith, B., \& Dutton, J. (2012). Schools that learn (updated and revised): A fifth discipline fieldbook for educators, parents, and everyone who cares about education. Crown Business. https://doi.org/10.1177/103841620101000313

[48] Janus, M., \& Offord, D. R. (2007). Development and psychometric properties of the Early Development Instrument (EDI): A measure of children's school readiness. Canadian Journal of Behavioural Science/Revue canadienne des sciences du comportement, 39(1), 1. https://doi.org/10.1037/cjbs2007001

[49] Sheridan, S. M., Marvin, C., Knoche, L., \& Edwards, C. P. (2008). Getting ready: Promoting school readiness through a relationship-based partnership model.

[50] Sheridan, S. M., \& Kratochwill, T. R. (2007). Conjoint behavioral consultation: Promoting family-school connections and interventions. Springer Science \& Business Media.

[51] Wright, C., Diener, M., \& Kay, S. C. (2000). School readiness of low-income children at risk for school failure. Journal of Children and Poverty, 6(2), 99-117. https://doi.org/10.1080/713675961

[52] Scott-Little, C., Kagan, S. L., \& Frelow, V. S. (2006). Conceptualization of readiness and the content of early learning standards: The intersection of policy and research? Early Childhood Research Quarterly, 21(2), 153-173. https://doi.org/10.1016/j.ecresq.2006.04.003

[53] Zafiropoulou, M., Sotiriou, A., \& Mitsiouli, V. (2007). Relation of self-concept in kindergarten and first grade to school adjustment. Perceptual and motor skills, 104(3_suppl), 1313-1327. https://doi.org/10.2466/pms.104.4.1313-1327

[54] Drigas, A., \& Karyotaki, M. (2016). Online and other ICT-based Assessment Tools for Problem-solving Skills. International Journal of Emerging Technologies in Learning (iJET), 11(04), 56-60. https://doi.org/10.3991/ijet.v11i04.5339

\section{Authors}

Georgia Kokkalia (MSc in Specific Learning Difficulties) is a Special Education Teaching Professional and Phd Candidate in University of Athens. She has participated in various research projects regarding the use of Information and Communication Technologies (ICTs) in Special Education and in Kindergarten (E- mail: gioulina@hotmail.com). 
Athanasios Drigas is a Research Director at N.C.S.R. 'Demokritos', Institute of Informatics and Telecommunications, Telecoms Lab - Net Media Lab, Agia Paraskevi, 153 10, Athens, Greece (e-mail: dr@iit.demokritos.gr).

Alexandra Economou is an associate professor at the University of Athens in the department of Psychology. She teaches undergraduate and postgraduate neuropsychology and experimental psychology courses at the University of Athens in the Department of Psychology while her interests focus on cognitive and biological psychology. Dr. Economou is also vice-president of the Greek Aphasia Association (E-mail: aoikono@psych.uoa.gr)

Petros Roussos is an assistant professor at the University of Athens in the department of Psychology. Since 1994 he has taught cognitive psychology, research methods and statistics in psychology at the University of Crete (Greece), the University of the Aegean (Greece), the University of Athens and many other colleges and higher education institutions. He has served as adjunct research fellow of the Hellenic Pedagogical Institute (1998-2000), as Psychology Department Chair at the University of Indianapolis Athens Campus (2000-2004) and as Researcher at the Unit of Analysis and Documentation at the Greek Ministry of Employment and Social Protection (2004-2005). He is also a graduate member of the British Psychological Society, member of the Hellenic Psychological Society, and General Secretary of the Hellenic Cognitive Science Society (E-mail: roussosp@psych.uoa.gr).

Article submitted 2019-01-04. Resubmitted 2019-03-09. Final acceptance 2019-03-10. Final version published as submitted by the authors. 